\title{
COOPERATIVE AND COMPETITIVE TEACHING TECHNIQUES AFFECTING IRANIAN EFL LEARNERS' AUTONOMY LEVEL
}

\author{
ABBAS ALI ZAREIA1 \& HAMIDE LAYEQB \\ almam Khomeini International University (Iran) / bIslamic Azad University (Iran)
}

\begin{abstract}
This study investigated the effects of competitive and cooperative teaching techniques on Iranian adult EFL learners' autonomy. To this end, a sample of 88 non-English major university students at Sohrevardi Nonprofit College in Qazvin were assigned to two groups, and each group received instruction under one of the treatment conditions including cooperative and competitive teaching techniques. To collect data, the Persian translation of an autonomy questionnaire was administered before and after the treatment. The obtained data were analyzed using an Analysis of Covariance (ANCOVA) procedure. The result of data analysis showed that competitive and cooperative teaching techniques affected the level of autonomy in EFL learners. The learners in the cooperative group were more autonomous. The findings of the present study may have implications for learners, teachers, and syllabus designers.
\end{abstract}

Keywords: Competitive teaching techniques, cooperative teaching techniques, learner autonomy

\section{Introduction}

The need to learn a foreign language is almost as old as human history itself (Wikipedia). Recently, this need has been felt more seriously due to increasing globalization as well as the need for using a common language in areas such as trade, international relations, technology, media, and science. As English is the international language, many researchers have focused on different methods of teaching to find optimal methods and techniques to implement in language classrooms. The history of language teaching methodology has experienced substantial changes from the period of grammar-translation method to the communicative language teaching, task-based approach, learning strategy training and cooperative learning (Brown, 2000). According to Johnson and Johnson (2009), experiential learning and student-centered learning, introduced by philosopher Dewey, and social psychologists Piaget and Vygotsky, is a base for collaborative learning.

Johnson and Johnson (2009) hold that researchers such as Sexton began to criticize competition in late 1960s, and social scientists (Hartup, 1976; Johnson, 1980; Johnson \& Johnson, 1981; Ladd, 1999; Lewis \& Rosenblum, 1975 ) pointed out the necessity of peer interaction. Then, cooperative learning became popular from 1980s, with the advent of communicative language teaching approach, which gave emphasis to the communicative aspects of language, and the task-based approach, which created the context for cooperative learning.

The concepts of autonomy and independence play an increasingly important role in language education. The major concerns here are issues such as learners' responsibility for their own learning, and their right to determine the direction of their own learning, the skills which can be learned and applied in self-directed learning, the capacity for independent learning and the extent to which this can be suppressed by institutional education (Little, 1991). According to Cooke (2013), autonomous practices might allow students greater opportunity to reflect upon their own and their classmates' performance and begin to incorporate more collaborative elements, such as inviting others to share their opinion or to demonstrate misunderstanding of their speech.

\footnotetext{
1 E-mail: a.zarei@hum.ikiu.ac.ir
} 
Many researchers have given attention to learner autonomy and autonomous learning as an important factor in successful learning, and many studies have been carried out on different factors that make learners more autonomous. However, few studies have considered the effect of teaching techniques on the level of learner autonomy. Therefore, this study aims to investigate the effect of competitive and cooperative teaching techniques on learner autonomy. With regard to what was mentioned above, by considering the significance of creating learning contexts to develop communicative competence and self-directed learners, this study aims to compare the effects of competitive and cooperative teaching techniques on the extent to which these contexts lead to more autonomous learning. More specifically, this study aims to find answers for the following research question:

Is there any significant difference between the effects of competitive and cooperative teaching techniques on Iranian adult EFL learners' autonomy?

\section{Literature review}

\subsection{Cooperative learning}

Gokhale (1995) defines cooperative learning as grouping and pairing of students at various performance levels to work together in small groups to monitor themselves and evaluate their own and others to achieve an academic goal. Zhang (2010) implies that more participation will inevitably increase self-confidence and self-esteem. Therefore, learners in cooperative learning environments are more active participators and more autonomous learners.

More than 1300 research studies have been conducted in the past 2 decades on cooperative, competitive, and individualistic efforts. The findings of these studies have validated, modified, refined, and extended the social interdependence theory which is a base for cooperative learning (Johnson \& Johnson, 2009). Cooperative or collaborative learning is based on the work of the philosopher Dewey, and social psychologists Piaget and Vygotsky about experiential learning and student-centered learning.

Hung, Mehl and Holen (2013), in a study on the relationship between problem design and learning process in a problem-based environment, found that problem-based learning is a kind of cooperative technique which improves critical thinking and makes learners ready to undertake tasks in the real world. They concluded that the kind of problems in this environment affects learners' cognitive level and influences learners' perception psychologically.

Kim and McDonough (2011) aimed to find the impact of pre-task modeling on the collaborative opportunities that occurred during three types of task performance of 44 adolescent Korean EFL learners including: dictogloss, decision-making, and information-gap. Half of the learners viewed videotaped models of collaborative interaction prior to carrying out the tasks, while others did not receive pre-task modeling. The interaction between the learners was analyzed in terms of the type and resolution of language related episodes (LREs) and learners' pair dynamics. The authors concluded that in terms of the total number of LREs, the pre-task modeling group produced a larger number of both grammatical and lexical LREs than the control group. In terms of lexical LERs, the pre-task modeling group produced more LREs for all three types of tasks. However, in terms of grammatical LREs, the pre-task modeling group produced more grammatical LREs than the control group in dictogloss task and information-gap task. Nevertheless, they had a similar number of grammatical LREs for decision-making task. Kim and McDonough also showed that the students in the pre-task modeling group had more collaborative interaction for all three types of tasks.

Furthermore, Hanz and Berger (2007) compared the effects of jigsaw and traditional direct instruction and found no significant difference in academic achievement of learners. However, there were strong positive effects of cooperative learning in the experience of three basic needs: autonomy, social relatedness and competence, which is central in explaining the benefits of cooperative learning. Furthermore, motivation and activation of deeper level of processing were improved in cooperative learning environment.

In another study, Sachs, Candlin and Rose (2003) studied the effect of cooperative learning on EFL/ESL secondary students' learning in Hong Kong. The results showed no significant difference in the oral performance of 
the experimental and control groups, but the authors concluded that the students engaged in discussions in cooperative learning environment felt more relaxed and more motivated.

Gaith (2003) studied the impact of cooperative learning on reading improvement, academic self-esteem and decreasing the feeling of school alienation of 56 Lebanese high school ESL learners. Gaith found a statistically significant difference in favor of the experimental group in reading achievement. However, there was no statistically significant difference between the control group and the experimental group in variables including academic selfesteem and feeling of school alienation.

\subsection{Learner autonomy}

Autonomy has been defined by many educators in different ways based on different factors such as the writer, the context, etc. It has been considered as a personal trait, a political measure, or an educational move. This is due to the fact that autonomy is seen either (or both) as a means or as an end in education. Dikinson (1995, p.167) believes that "autonomy can be seen as an attitude towards learning in which the learner is prepared to take, or does take responsibility for his own learning." Bruce's (1995) definition is quite similar to Dickinson's definition. Cortes and Lujan (2005, p.134) define autonomy as "moving away from conventional and restrictive context and moving towards selfdirection and self-regulation." Smith (2008) refers to Holec, the father of learner autonomy, defining autonomous language learners as learners who take responsibility for the totality of their learning situation. The learners do this by determining their own objectives, defining the content to be learned, progression of the course, selecting methods and techniques to be used, monitoring this procedure, and evaluating what they have acquired. The operational definition given by Little (1991) is that practice of learner autonomy requires insight, positive attitude, capacity for reflection, and readiness to be proactive in self-management and in interaction with others. According to Benson (2011, p. 124), autonomy and autonomous learning is "learning in which autonomous learners demonstrate a capacity to control their learning". Autonomous behavior is developed through practice in such a way that helps to promote self-direction.

Several studies have been conducted on various aspects of learner autonomy. Cooke (2013) investigated the effect of transcription and reflective practice on learners' autonomy. The results of the study showed that transcription and reflective practice could help the development of noticing, arguably a key element in autonomous acquisition of new language and language development. Moreover, collaborative techniques encouraged peer evaluation and feedback.

Ma and Gao (2010) investigated the effect of the provision of contexts for language learning on autonomous learning through ongoing process of negotiations. They concluded that negotiations of purpose, contents, and evaluation make students highly motivated and more responsible for their own learning.

Yahong (2009) investigated the effects of instruction, goal definition, and encouragement on learner autonomy and concluded that the above variables had positive effect on learners' autonomy level.

Murphy (2008) investigated how distance language course materials support the development of critical reflection and autonomy. The author referred to critical reflection, metacognitive strategies, self-assessment, interaction and collaboration as the key criteria in automatization. She concluded that distance course materials make learners more autonomous.

Po-Ying (2007) investigated how students react to assuming responsibility for their own learning by understanding their experience, encouraging self and peer evaluation, brainstorming, and focusing on areas of strength. The results showed that the students become decision-makers and actively engaged in learning.

Chang (2007) investigated the impact of group processes on Taiwanese EFL learners' autonomy, their autonomous beliefs and behaviors. The results showed a moderate correlation between group processes (both cohesiveness and group norms) and individual learners' autonomous behaviors. However, there was no significant correlation between group processes and individual learners' autonomous beliefs. As learner autonomy plays an important role in long life English learning and teaching, Duan (2005) suggested four effective ways including 
changing the beliefs of teachers and learners, teaching learning strategies, using cooperative learning, and taking advantage of computer resources to foster it.

Garrett and Shortall (2002) investigated the relationships among enjoyment, anxiety, and learning value of 103 Brazilian EFL students at different proficiency levels: beginners, elementary, and intermediate with different types of classroom interaction: pair work and small group work and learning activities: teacher-fronted grammar (TFG), student-centered grammar (SCG), teacher-fronted fluency (TFG), and student-centered fluency (SCF). They concluded that there were significant differences among the students at different levels. Beginners found TFG better than SCF. Intermediate learners saw TFG as less fun, however they indicated that SCF is more fun and more relaxing than TFF. Though neither of them perceived any difference between types of learning activities in their relaxation and enjoyment, for learning they preferred TFF.

Furthermore, Spratt, Humphreys and Chan (2002) investigated the relationship between autonomy and motivation, and proposed a more complex relationship in contrast to those who consider motivation as a product of autonomy by assessing students' readiness for learner autonomy in language learning and their level of motivation to learn English. The results revealed that motivation played a key role in determining the level of learners' autonomy.

Cotterall (2000) proposed principles to foster leaner autonomy including 1) learner goal, 2) the language learning process, 3) tasks, 4) learner strategies, and 5) reflection on learning. She concluded that the inclusion of tasks related to learners' goal (principles $1 \& 3$ ) resulted in unprecedented levels of motivation. Moreover, learners improved their ability to assess their own performance. With regard to principles 2 and 4 , learners reported that the incorporation of materials on language learning process and learner strategies provided the learners with a model for solving their own learning problems and proved an efficient solution to the problem of limited time.

Based on what was mentioned above, it may be concluded that there are differences in competitive and cooperative learning contexts with regard to the teaching techniques, the kinds of feedback, and the learners' dependence on teachers and other classmates. The aim of this study is to compare the effects of these contexts on learner autonomy.

\section{Methodology}

\subsection{Participants}

The participants of the present study were a sample of 88 adult, male and female, EFL learners studying English for general purposes in Sohrevardi Nonprofit College in Qazvin. 44 students were in the competitive learning group and 44 in the cooperative learning group.

\subsection{Instrument}

To answer the research question of the study, the Persian translation of an autonomy questionnaire including 21 items which was scored on a five-point scale and coded as (A. never, B. rarely, C. sometimes, D. often, E. always) taken from Zarei and Elekai (2012) and translated by the researcher was used. The reliability of the questionnaire was estimated using Cronbach's alpha, and it turned out to be 0.83 .

\subsection{Procedure}

To achieve the purpose of this study, the following procedure was followed:

First, in order to encourage the participants to answer the questions honestly and without anxiety, the participants were informed about the aims and the purposes of the study. Then, the questionnaire was given to the participants in two stages. 
In the first stage, the autonomy questionnaire was given to all of the participants to capture their initial differences. In this stage, the participants had 45 minutes to answer the questions. If the participants had any questions, their questions were answered in Persian.

Then the participants were assigned to two groups. In the cooperative group, the participants were divided into groups of four or five members. They were given instructions through cooperative techniques including discussion, reciprocal teaching techniques, graphic-organizer and problem-solving. The participants of the other group were engaged in traditional, competitive activities in which the teacher explained the grammar and presented the new words of the passage. Each student worked individually and answered the questions on the grammar section of the passage, and the teacher made corrections on their mistakes.

At the end of the instructional period, the autonomy questionnaire was administered again to measure the gain of the learners after the use of the competitive and cooperative teaching techniques. In this stage, 30 minutes were allocated for the questionnaires, and the researchers answered possible questions in Persian. The obtained data were then summarized and submitted to statistical analysis.

\subsection{Data analysis}

To analyze the data and to answer the research questions about the effects of competitive and cooperative learning techniques on learner autonomy, Analysis of Covariance (ANCOVA) procedure was used.

\section{Results and discussions}

\subsection{Results}

This study sought to find out the difference between the effects of the competitive and cooperative teaching techniques on Iranian EFL Learners' autonomy. To this end, an ANCOVA procedure was used. Table 1 contains the descriptive statistics and Table 2 shows the results of the ANCOVA procedure.

Table 1. Descriptive statistics for the ANCOVA on learners' autonomy

\begin{tabular}{lrrr}
\hline Group & Mean & Std. Deviation & \multicolumn{1}{l}{ N } \\
\hline Competitive group & 60.68 & 14.746 & 44 \\
Cooperative group & 72.93 & 7.908 & 44 \\
Total & 66.81 & 13.279 & 88 \\
\hline
\end{tabular}


Table 2. ANCOVA results on learners' autonomy

\begin{tabular}{lccccccc}
\hline Source & $\begin{array}{c}\text { Type II Sum } \\
\text { of Squares }\end{array}$ & df & $\begin{array}{c}\text { Mean } \\
\text { Square }\end{array}$ & F & Sig. & $\begin{array}{c}\text { Partial Eta } \\
\text { Squared }\end{array}$ & $\begin{array}{l}\text { Observed } \\
\text { Power }^{\mathrm{b}}\end{array}$ \\
\hline Corrected Model & $9605.92^{\mathrm{a}}$ & 2 & 4802.96 & 71.201 & .00 & .626 & 1.000 \\
Intercept & 4038.95 & 1 & 4038.95 & 59.875 & .00 & .413 & 1.000 \\
Pre-autonomy & 6304.55 & 1 & 6304.55 & 93.461 & .00 & .524 & 1.000 \\
Group & 5183.61 & 1 & 5183.61 & 76.844 & .00 & .475 & 1.000 \\
Error & 5733.78 & 85 & 67.45 & & & & \\
Total & 408097.00 & 88 & & & & & \\
Corrected Total & 15339.71 & 87 & & & & & \\
\hline \multicolumn{7}{l}{ a. R Squared $=.626$ (Adjusted R Squared $=.617)$} \\
b. Computed using alpha $=.05$
\end{tabular}

As Table 2 shows, there is a significant difference between the effects of competitive and cooperative teaching techniques on the level of learner autonomy $\left(F_{(1,87)}=76.84, P<.01\right)$. Meanwhile, the index of the strength of association $\left(\eta^{2}=.47\right.$ ) indicates that about $47 \%$ of the observed differences between the groups is attributable to the independent variable (cooperative versus competitive presentation techniques). This means that the remaining $53 \%$ of the variance is left unaccountable for. However, since the $F$-ratio and the significant level $\left(F_{(1,87)}=93.461, P<.01\right)$ are also indicative of a significant difference between the two groups prior to the treatment, the result of the posttest is somewhat overshadowed. This means that care must be exercised in interpreting the result.

\subsection{Discussion}

The present study attempted to investigate the effects of competitive and cooperative teaching techniques on learner autonomy.

The finding of the present study showed that there was a significant difference between the effects of competitive and cooperative teaching techniques on learners' autonomy and showed that learners in the cooperative context are more autonomous. This finding is compatible with that of Ma and Gao (2010), who found that collaborative learning was a foundation of autonomy, and reported that collaborative learning makes students more responsible and more open-minded to others' ideas. Moreover, the finding of the present study is in line with the findings of Murphy (2008), who showed that cooperative and collaborative learning make learners more autonomous.

The finding of the present study may have been affected by several variables including the following:

According to Radwan (2011), Rao (2006) and Sheory (1999), social and cultural factors affect learner autonomy. So, these factors may also have influenced autonomy level. In addition, Radwan (2011) suggests that gender affects learners' autonomy level. As this study did not consider gender as a variable, the findings may have been affected by the gender of the learners. Furthermore, the level of learners' autonomy at different age levels is different. This study did not consider age as a variable. Therefore, the findings of the study may have been affected by the age of the participants. Moreover, while there were differences between the participants' performance on the post test, there were also significant differences in their pretest results. This implies that one cannot safely claim that the differences in the posttests were necessarily because of the effect of the treatment. Due to the uncertainties about the obtained result more replication studies are needed to shed light on the issue addressed in this study.

\section{CONCLUSIONS}

The present study attempted to investigate the effects of competitive and cooperative teaching techniques on learners' autonomy. The finding of the study indicated that cooperative teaching techniques affect and learners' autonomy positively. The result revealed that cooperative teaching techniques improve learner autonomy. Based on 
the finding of this study, it could be concluded that, contrary to learners' natural intuition that learner autonomy requires working independently from others, learners may actually attain a higher level of autonomy when they are engaged in cooperative learning activities. This might be partly due to higher levels of self-confidence they may attain in cooperative contexts. Nonetheless, it is concluded that learners need to be encouraged to work together to achieve higher levels of autonomy. Since nowadays, in many educational contexts, there are calls for learner autonomy, it may also be concluded that there is a need to change the competitive teaching techniques to cooperative teaching techniques. This means that teachers need to become more familiar with cooperative teaching techniques. One may also conclude that syllabus designers and those involved in materials preparation need to take care to change the nature of the activities in books and to include more cooperative activities in course books to encourage learners to work cooperatively. If this happens, course books can also act as agents of change, pushing teachers - naturally resistant to change - to adopt teaching techniques requiring cooperative work.

\section{References}

Benson, P. (2011). Teaching and Researching Autonomy, Second Edition. Harlow: Pearson Education Limited.

Brown, H.D. (2000). Principles of language learning and teaching. New York: Longman.

Bruce, N. (1995). Practising what we preach: Creating the conditions for student autonomy. Hong Kong Papers in Linguistics and Language Teaching, 18, 73-88.

Chang, L. Y-H. (2007). The influences of group processes on Learners' autonomous beliefs and behaviors. System, $35,322-337$.

Cooke, S.D. (2013). Examining Transcription, Autonomy and Reflective Practice in Language Development, RELC Journal, 44(1), 75-85.

Cortes, M.L. and Lujan, D.K.S. (2005). Profiles of autonomy in the field of foreign languages. Profile, 6, 133-140.

Dikinson, L. (1995). Autonomy and motivation: A literature review. System, 23(2), 165-174.

Duan, L. (2005). How to Foster Learner Autonomy in English Teaching and Learning. Sino-US English Teaching, 2(7), 45-47.

Gaith, G.H. (2003). Effects of the Learning Together Model of Cooperative Learning on English as Foreign Language Reading Achievement, Academic Self-Esteem, and Feeling of School Alienation. Bilingual Research Journal, 27(3), 451-474.

Garrett, P. and Shortall, T. (2002). Learners' evaluations of teacher-fronted and student-centered classroom activities. Language Teaching Research, 6(1), 25-57.

Gokhale, A.A. (1995). Collaborative Learning enhances critical thinking. Journal of Technology \& Education, 7(1), 2230.

Hanze, M. and Berger, R. (2007). Cooperative Learning, motivational effects, and students' characteristics: An experimental study comparing cooperative learning and direct instruction in 12thgrade physics classes. Learning and instruction, 17, 29-41.

Holec, H. (1981). Autonomy and foreign language learning. Oxford: Pergamon.

Hung, W., Mehl, K. and Bergland Holen, J. (2013). The relationship between Problem Design and Learning Process in Problem-Based Learning Environment: Two Cases. The Asia-Pacific Education Researcher, 22(4), 635645.

Johnson, D.W. and Johnson, R.T. (2009). An Educational Psychology Success story: Social Interdependence Theory and cooperative learning. Educational Research, 38(5), 365-379.

Kim, Y. and McDonough, K. (2011). Using pre-task modeling to encourage collaborative learning opportunities. Language Teaching Research, 15(2), 183-199. 
Little, D. (1991). Learner Autonomy. 1: Definitions, Issues, and Problems. Dublin: Authentic Language Learning Resources Ltd.

Ma, Z. and Gao, P. (2010). Promoting Learner Autonomy through Developing Process Syllabus - Syllabus Negotiation: the basis of Learner Autonomy. Journal of Language Teaching and Research. 1(6), 901-908.

Murphy, L. (2008). Supporting learner autonomy: Developing practice through the production of courses for distance learners of French, German and Spanish, Language Teaching Research, 12(1), 83-102.

Po-ying, Ch. (2007). How students react to the power and responsibility of being decision makers in their own learning, Language Teaching Research, 11(2), 225-241.

Sheorey, R. (1999). An examination of language learning strategy use in the setting of an indigenized variety of English. System, 27, 173-190.

Smith, R. (2008). Key Concept in ELT: Learner Autonomy, ELT Journal, 62(1), 395-397.

Spratt, M., Humphreys, G., and Chan, V. (2002). Autonomy and Motivation: which comes first? Language Teaching Research, 6(3), 245-266.

Radwan, A.A. (2011). Effects of L2 proficiency and gender on choice of language learning strategies by university students majoring in English. Asian EFL Journal, 13(1), 114-162.

Rao, Z. (2006). Understanding Chinese students' use of language learning strategies from cultural and education perspective. Journal of Multilingual and Multicultural Development, 27(6), 491-508.

Tinker Sachs, G., N. Candlin, Ch. and R. Rose, K. (2003). Developing cooperative Learning in EFL/ESL Secondary classroom. RELC Journal, 34(3), 338-369.

Yahong, L. (2009). How Can I Help My Students Promote Learner-Autonomy in English Language Learning. Educational Journal of Living Theories, 2(3), 365-398.

Zarei, A.A. and Elekaei, A. (2012). Learner Autonomy and Language Learning Strategies. LAP: LAMBERT Academic Publishing.

Zhang, Y. (2010). Cooperative language learning and foreign language learning and teaching. Journal of Language Teaching and Research, 1(1), 81-83.

Received: 08/03/2016

Accepted: 15/05/2016 